\title{
Influence of Grid on pkHRR Test of Cone Calorimeter
}

\author{
XIE Weibin ${ }^{1, a^{*}}$, WANG $\operatorname{Ran}^{2, b}$ and WANG Xiaochun ${ }^{2, c}$ \\ ${ }^{1}$ Zhejiang Academy of Science \&Technology for Inspection \& Quarantine, Hangzhou 311215, \\ China; \\ ${ }^{2}$ School of Material Science and Engineering, Beijing Institute of Fashion Technology, Beijing \\ 100029, China

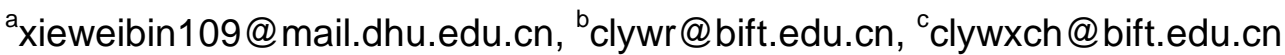

Keywords: cotton; PET; flame-retard; Cone; C.V

Abstract. Influence of grid on peak of Heat Release Rate (pkHRR) test of cone calorimeter was researched, in which cotton, flame-retard cotton, PET, and flame-retard PET fabric were used. Results show that coefficients of variation (C.V) of pkHRR values of cotton and flame-retard cotton were reduced from $8.5 \%$ and $11.1 \%$ to $4.6 \%$ and $4.3 \%$, respectively. PkHRR values of PET and flame-retard PET fabric turned from abnormal distribution to normal distribution. C.V of pkHRR values tested with grid of PET and flame-retard PET fabric were $7.2 \%$ and $8.9 \%$, respectively. Those demonstrate that adoption of grid increases significantly repeatability of pkHRR values of those fabrics.

\section{Introduction}

The cone calorimeter, a new generation apparatus to measure combustibility, is based on the oxygen consumption. When per unit mass of oxygen is consumed by the completely combustion of the majority of organic gases, liquids or solids, the neat heat released is a constant of $13.1 \pm 5 \% \mathrm{MJ} / \mathrm{kg}^{[1,}{ }^{2]}$. In 1982 , according to this principle, the new calorimeter was developed by the national standards and technology research institute. Because of its conical irradiation heater, it is named of cone calorimeter.

Compared with the other test methods, the combustion environment of cone calorimeter is very similar to the real fire environments. Due to a good correlation between the test results of cone and large combustion test results, it can be used to analysis the combustion performance of materials and to estimate the fire risk of materials in real. It has important reference value in the evaluation of materials, materials design and fire prevention, and so on. Therefore, the cone calorimeter has be of a very important instrument to study the combustion performance of materials ${ }^{[3,4]}$.

In generally, the test objects of the cone calorimeter was mainly concentrated on the materials with the thickness more than of $6 \mathrm{~mm}$ and the burning time more than several minutes. But textiles can not usually reach these requirements. On the basis of the standards of ISO 5660-1 and ASTME 1354, textiles were detected by Horrocks A. Richard, specialist in flame research. Because textiles thickness was too small and inside temperature of textiles heated by radiation achieved uniform so quickly, the data reproducibility of test was found to be poor, and it is necessary to establish new test methods for textiles $^{[5]}$. In order to improve the accuracy of test data, Schartel B, Germany, definitely proposed that the test conditions of the existing standards of ISO, ASTM and other should be studied and optimized for textiles ${ }^{[6]}$. But in recent years, the related research report is less.

Grid, a net device made of stainless steel wire, is used across the surface of the sample to prevent the sample warping and avoid big change of burning surface area.

According to accurately detect gas flow rate and oxygen concentration during the combustion process of materials tested by cone calorimeter, the instantaneous heat release rate(HRR) is achieved. Total heat release and other combustion data is calculated on the base of HRR, therefore, heat release rate is a importantly fundamental data for the cone calorimeter. Heat release rate is variable in burning process and affected by many factors. The maximum heat release rate (peak of HRR, referred to as 
pkHRR), reflects the instantaneously maximum damage of textile burning to the human body and has a certain stability.

In order to improve test repeatability of the method, The effects of grid on pkHRR was researched, in which cotton, flame-retard cotton, PET and flame-retard PET fabric were used.

\section{Experiment}

Materials. The specification of tested fabric were shown in Table 1. Grid was a attachment of the cone calorimeter and a net device made from 10 stainless steel with long $100 \mathrm{~mm}$ and diameter $2 \mathrm{~mm}$.

Table1 Specification of tested fabric

\begin{tabular}{cccc}
\hline Order number & fabric name & $\begin{array}{c}\text { Warp and weft density }( \\
\text { root } / 10 \mathrm{~cm})\end{array}$ & Weight $\mathrm{g} / \mathrm{m}^{2}$ \\
\hline 1 & cotton fabric & $500 \times 250$ & 145 \\
2 & PET fabric & $770 \times 320$ & 110 \\
3 & flame-retard cotton & $600 \times 250$ & 280 \\
4 & flame-retard PET & $600 \times 450$ & 210 \\
\hline
\end{tabular}

Test. According to ISO5660-1:2002 Reaction to fire tests-Heat release, smoke production and mass loss rate-Part 1: Heat release rate (cone calorimeter method), the combustion performances of fabrics were tested by Dual Analysis Calorimeter 2000 (Fire Testing Technology, UK). the samples with size of $100 \mathrm{~mm} * 100 \mathrm{~mm}$ were placed on the aluminum foil, and the rock wool underneath aluminum foil was used to insulate heat transfer from the back of sample. the grid was between positioning frame and the sample. each sample was tested repeatedly at $25 \mathrm{kw} / \mathrm{m}^{2}$ heat flux. Data were analyzed by cone calorimeter software, and the normality of the data was examined by the Shapiro-Wilk test method (confidence level alpha $=0.5$ ).

\section{Results and Discussion}

Effect of grid on the pkHRR of cotton fabrics. The pkHRR of Cotton fabric and flame-retard cotton fabric was researched, and the data tested with grid or not were proved to be in line with the normal distribution by Shapiro-Wilk test method. As shown in Figure 1 and Figure 2, comparing the probability density function distribution of testing value of two kinds of fabric, the effect grid on pkHRR of fabrics was obvious. When grid was not used in the combustion test, the mean value of pkHRR of Cotton fabric, variance and coefficient of variation (C.V) were $338.7 \mathrm{KW} / \mathrm{m}^{2}, 838.7,8.5 \%$ separately. After using gird, the mean value of pkHRR of cotton fabric, variance and C.V were respectively reduced to $16.88 \mathrm{KW} / \mathrm{m}^{2}, 60.2,4.6 \%$, and the mean value of pkHRR of flame cotton fabric, variance and coefficient of variation were reduced from $224.1 \mathrm{KW} / \mathrm{m} 2,618.9,11.1 \%$ to $118.0 \mathrm{KW} / \mathrm{m} 2,25.8,4.3 \%$ respectively. 


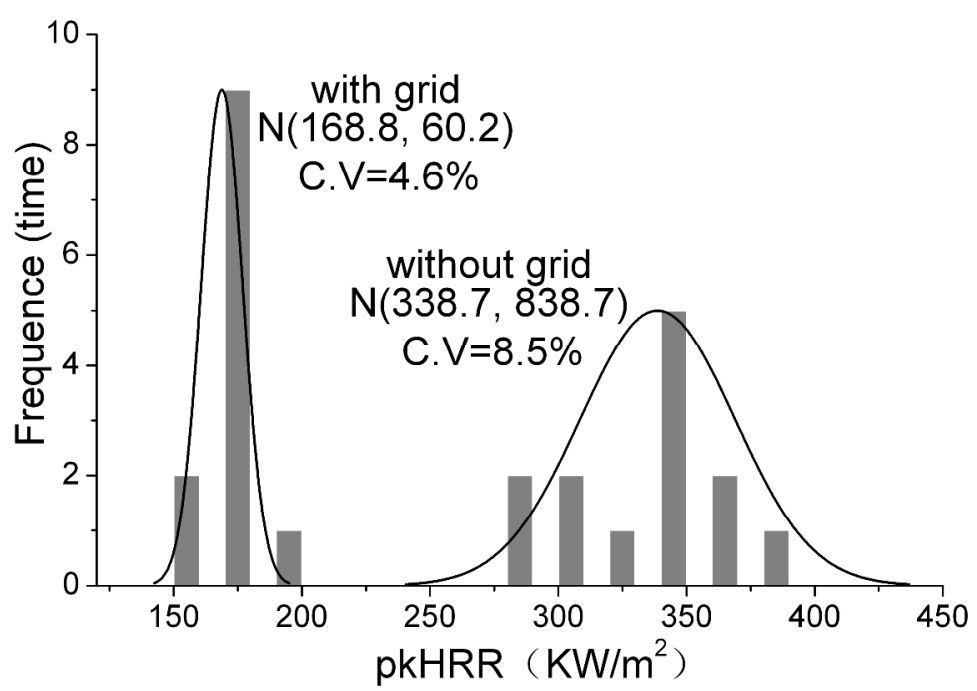

Fig.1 Effect of grid on the pkHRR of cotton fabric

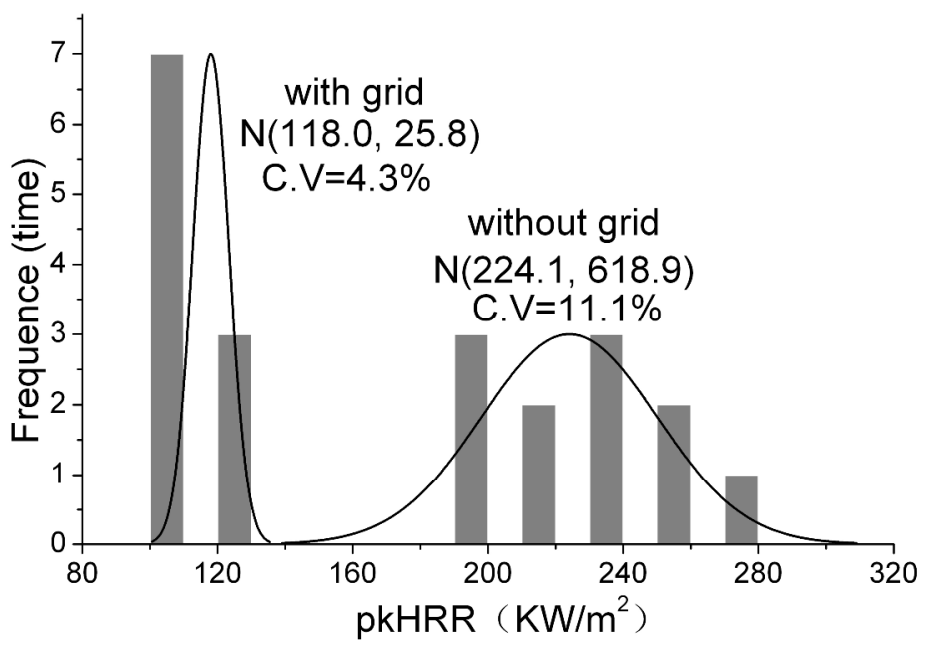

Fig.2 Effect of grid on the pkHRR of flame-retard cotton fabric

Once using grid for testing the same sample, the mean value of pkHRR decreased. It meant that, though the correlation between test results of the cone calorimeter and results of large combustion did not be destroyed, the correlation of them needed to be make some adjustments. Due to the obvious difference of pkHRR value with grid or not, the dispersion degree of data was not suitable to characterize directly with the variance or standard deviation, and should be described with C.V calculated by the mean value and the variance. Because of the significantly decrease of C.V of test value, it was concluded that the data dispersion was reduced and test repeatability was improved remarkably. Namely, if an operator in the same laboratory used the same cone calorimeter to measure the same samples for mutually independent detection, the consistency of test results would be significantly improved.

Effect of grid on the pkHRR of PET fabrics. As shown in Tab.2 and 3, whether the grid was used or not, the pkHRR of PET fabric and flame-retard PET fabric was researched.

When grid didn't be used, the differences of pkHRR value between repeated tests were obviously. Test results of PET fabric or flame-retard PET fabric were proved to be abnormal distribution by Shapiro-Wilk test method(confidence for alpha $=0.5$ ). This may be that PET is hot melting material, and when heated, melting shrinkage was occurred from a point of fabric as the center. Due to random of the position of melting shrinkage occurred, electronic ignition device of cone calorimeter cannot accurately moved to flammable gas released by melting shrinkage above, and it resulted that fabric could not be ignited and caused a large experimental error. 
When grid was used in test, melting shrinkage of PET was occurring around the stainless steel wire of grid as the center, the experimental data were coincided with the normal distribution by Shapiro-Wilk test method(confidence for alpha $=0.5$ ). For PET fabric and flame-retard PET fabric, the C.V of pkHRR were $7.2 \%$ and $8.9 \%$ respectively and similar with those of cotton fabric and flame-retard cotton fabric. It is concluded that the data dispersion was reduced and test repeatability was improved obviously.

Table 2 effect of grid on the pkHRR of PET fabric

\begin{tabular}{|c|c|c|c|c|c|c|c|}
\hline & \multicolumn{6}{|c|}{ pkHRR ( KW/m²) } & dada distribution \\
\hline $\begin{array}{l}\text { without } \\
\text { grid }\end{array}$ & 15.9 & 164.9 & 89.59 & 152.3 & 149.0 & 49.7 & $\begin{array}{c}\text { abnormal } \\
\text { distribution } \\
\text { normal } \\
\text { distribution }\end{array}$ \\
\hline with grid & 88.2 & 105.5 & 90.7 & 95.6 & 84.3 & 93.5 & $\begin{array}{c}\mathrm{N}(93.0,44.6 \\
) \\
\text { C. } V=7.2 \%\end{array}$ \\
\hline
\end{tabular}

Table 3 effect of grid on the pkHRR of flame-retard PET fabric

\begin{tabular}{cccccccc}
\hline & \multicolumn{4}{c}{$\operatorname{pkHRR}\left(\mathrm{KW} / \mathrm{m}^{2}\right)$} & & $\begin{array}{c}\text { dada } \\
\text { distribution }\end{array}$ \\
\hline $\begin{array}{c}\text { without } \\
\text { grid }\end{array}$ & 90.7 & 10.5 & 46.1 & 6.7 & 125.6 & 5.8 & $\begin{array}{c}\text { abnormal } \\
\text { distribution } \\
\text { normal } \\
\text { distribution }\end{array}$ \\
& & & & & & & \\
with grid & 146.7 & 160.2 & 164.9 & 178.3 & 150.6 & 188.3 & $\mathrm{~N}(164.8$, \\
& & & & & & & $213.7)$ \\
& & & & & & & C.V $=8.9 \%$ \\
\hline
\end{tabular}

\section{Conclusion}

Grid can effectively decrease the C.V of pkHRR of cotton, flame-retard cotton, PET and flame-retard PET and can improve obviously the repeatability of test.

Compare with no grid, the C.V of pkHRR of cotton and flame-retard cotton with grid reduced to $4.6 \%$ and $4.3 \%$ respectively.

For PET and flame-retard PET, Compare with no grid, the experimental data of pkHRR with grid turned from abnormal distribution to normal distribution by Shapiro-Wilk test method(confidence for alpha $=0.5$ ). C.V of pkHRR values tested with grid of PET and flame-retard PET fabric were $7.2 \%$ and $8.9 \%$, respectively.

\section{Acknowledgements}

This work was financially supported by General Administration of Quality Supervision, Inspection and Quarantine of the People's Republic of China R\&D Program (No. 2014IK162) and the Beijing Institute of Fashion Technology young innovation fund Program(No. 2014AL-20).

\section{References}

[1]W. M. Thornton. The relation of oxygen to the heat of combustion of organic compounds[J]. Philosophical Magazine Series 6, 1917, 33: 196-203. 
[2]C. Huggett. Estimation of rate of heat release by means of oxygen consumption measurements[J].Fire and Materials, 1980, 4 (2): 61-65.

[3]HAO Quan , JIANG Shu-guang, WEI Ai-zhu , etc.Application of cone calorimeter in research of fire science[J]. Energy Technology and Management, 2009, (1): 2-75.

[4] Wang Qingguo , Zhang Jun, Zhang Feng. The principle and application of the cone calorimeter [J].Modern Sceintific Instruments, 2003, 6: 36 - 39.

[5]S. Nazaré, B. Kandola, A. R. Horrocks. Use of cone calorimetry to quantify the burning hazard of apparel fabrics[J].Fire and Materials, 2002, 26: 191-199.

[6]Schartel B , Hull TR. Development of fire-retarded materials-Interpretation of cone calorimeter data[J]. Fire and Materials, 2007, 31:327-354. 